\title{
The value of glioma extent of resection in the modern neurosurgical era
}

\section{Douglas A. Hardesty and Nader Sanai*}

Division of Neurological Surgery, St. Joseph's Hospital and Medical Center, Barrow Neurological Institute, Phoenix, AZ, USA

Edited by:

Kerrie L. McDonald, University of

New South Wales, Australia

Reviewed by:

Han Shen, University of New South

Wales, Australia

Jonathon Parkinson, University of

Sydney, Australia

*Correspondence:

Nader Sanai, Division of Neurological

Surgery, St. Joseph's Hospital and

Medical Center, Barrow Neurological

Institute, 310 North Third Avenue,

Phoenix, AZ 85013, USA.

e-mail:nader.sanai@bnaneuro.net

\begin{abstract}
Objective: There remains no general consensus in the neurosurgical oncology literature regarding the role of extent of glioma resection in improving patient outcome. Although the value of resection in establishing a diagnosis and alleviating mass effect is clear, there is less certainty in ascertaining the influence of extent of resection (EOR). Here, we review the recent literature to synthesize a comprehensive review of the value of extent of resection for gliomas in the modern neurosurgical era. Methods: We reviewed every major peerreviewed clinical publication since 1990 on the role of EOR in glioma outcome. Results: Thirty-two high-grade glioma articles and 11 low-grade glioma articles were examined in terms of quality of evidence, expected EOR, and survival benefit. Conclusion: Despite limitations in the quality of data, mounting evidence suggests that more extensive surgical resection is associated with longer life expectancy for both low- and high-grade newly diagnosed gliomas.
\end{abstract}

Keywords: glioma, extent of resection, low-grade glioma, high-grade glioma, malignant transformation

\section{INTRODUCTION}

Gliomas are the most common primary malignant brain tumor in adults, yet outcomes from this aggressive neoplasm remain dismal. In the modern era, the multimodal management of these tumors begins with microsurgical resection whenever possible. Advances in intraoperative technique, including neuronavigation, intraoperative magnetic resonance imaging, intraoperative ultrasound, stimulation mapping techniques, and fluorescence-guided surgery, have all been developed to maximize tumor resection and minimize surgical morbidity for both low- and high-grade gliomas (Barker et al., 1996; Stummer et al., 2006; Sanai and Berger, 2009, 2010; Kubben et al., 2011).

The elucidation of prognostic factors and treatment options for glioma remains a challenge. Patient age and tumor histology have been identified as reliable predictors of patient prognosis among tumor- and treatment-related variables, and patient functional status can also be predictive of outcome. The use of biomarkers such as IDH1/2 and MGMT-methylation status is increasingly common, although the exact role for such markers in routine clinical management remains undefined. The importance of surgical debulking in obtaining a tissue diagnosis and to alleviate symptoms from mass effect is clear, but a lack of Level I evidence limits certainty in assessing the influence of extent of resection (EOR). Despite significant advances over the last two decades in brain tumor imaging and intraoperative technology, the actual impact of glioma resection in extending tumor-free progression, patient quality of life, and patient overall survival remains unclear. With this in mind, we have examined every major clinical publication from 1990 to 2012 that reports on the role of EOR in glioma outcome. Our objective is to synthesize a comprehensive assessment of EOR in the modern neurosurgical era, as well as to critically examine the quality of evidence in the published literature. Lastly, we aim to identify the magnitude of improvement in patient survival, if any, that can be achieved with the degree of EOR.

\section{METHODS}

A literature search of the PubMed database from January 1990 to June 2012 was conducted using the following key words: "high-grade glioma," "low-grade glioma," “astrocytoma," "anaplastic astrocytoma," "oligodendroglioma," "oligoastrocytoma," and "glioblastoma (GBM)."

English-language series including adult patients with hemispheric gliomas were identified. Before analyzing the studies in detail, we conducted additional screening. Small series $(<75$ patients), or those with incomplete methodological data (such as specification of how EOR was assessed), were eliminated. Also excluded were those studies where EOR was recorded only as a volume of residual tumor, or those studies that only compared resection to biopsy. We excluded series that had both adult and pediatric patients if the adult patients had not been analyzed separately. Studies including pilocytic and gemistocytic astrocytomas, where data regarding patients with these tumors were not separated from other low-grade gliomas, were excluded. Based upon these criteria, we found 32 studies examining EOR for high-grade gliomas and 11 studies examining EOR for low-grade gliomas (Tables 1-6).

For these remaining studies, we considered the statistical analysis that affected interpretation of data. This assessment included the identification of potential methodological flaws and information that was omitted from the publication. The methodological parameters we evaluated included choice of statistical tests and adjustment for confounding variables. The specific information that we searched for consisted of discussion of possible sources of bias in selection of cases, number of events (deaths), length of follow-up for patients without events, i.e., survivors, hazard 
Table 1 | Volumetric EOR studies in high-grade glioma.

\begin{tabular}{|c|c|c|c|c|c|c|}
\hline \multirow[t]{2}{*}{ Study } & \multirow{2}{*}{$\begin{array}{l}\text { Tumor } \\
\text { grade(s) }\end{array}$} & \multirow[t]{2}{*}{ Patients } & \multirow{2}{*}{$\begin{array}{l}\text { Extent of } \\
\text { resection }(N)\end{array}$} & \multicolumn{3}{|c|}{ Overall survival } \\
\hline & & & & $\begin{array}{l}\text { Mean survival } \\
\text { (months) }\end{array}$ & $\begin{array}{l}\text { Univariate } \\
\text { analysis } p \text { value }\end{array}$ & $\begin{array}{l}\text { Multivariate } \\
\text { analysis } p \text { value }\end{array}$ \\
\hline \multirow[t]{3}{*}{ Keles et al. (1999) } & IV & 107 & $<25 \%(25)$ & 8.0 & NA & $<0.0005$ \\
\hline & & & $25-49 \%(21)$ & 14.2 & & \\
\hline & & & $100 \%(23)$ & 23.3 & & \\
\hline \multirow[t]{4}{*}{ Pope et al. (2005) } & IV & 110 & $<20 \%$ & 27.4 & NS & NS \\
\hline & & & $20-89 \%$ & 11.1 & & \\
\hline & & & $90-99 \%$ & 17.1 & & \\
\hline & & & $100 \%$ & 22.1 & & \\
\hline \multirow[t]{4}{*}{ Sanai et al. (2011) } & IV & 500 & $>77 \%$ & 12.5 & $<0.0001$ & 0.004 \\
\hline & & & $>79 \%$ & 12.8 & & \\
\hline & & & $>89 \%$ & 13.8 & & \\
\hline & & & $100 \%$ & 16 & & \\
\hline
\end{tabular}

ratios, and confidence intervals. We sought to identify potential confounders underlying predictor variables. For example, it could be possible that all patients in whom a subtotal resection (STR) was achieved underwent adjuvant chemoradiation and that none of those in whom a total resection was achieved underwent such therapy. We also looked for a specific statement of how the multivariate analysis, if any, was conducted. Because none of these studies were prospective randomized trials, we looked for how many patients were in each of the analyzed subsets, to determine if studies were adequately powered to see statistically significant differences.

Preoperative and postoperative tumor volumes, from which the EOR is calculated, have been considered as possible prognostic factors. We therefore identified publications to find studies that included evaluations of preoperative and residual tumor volumes on outcome. High-grade gliomas were in all series defined by the enhancing region on a T1-weighted MRI. For low-grade gliomas, tumor volume and EOR were calculated upon T2-weighted MR imaging. Tumor progression was defined by the radiographic progression of these MRI features. Studies using volumetric tumor analysis were evaluated separately, as this method can dramatically affect EOR calculations (Sanai and Berger, 2008, 2009).

\section{RESULTS}

\section{HIGH-GRADE GLIOMA STUDIES TO DATE - AN OVERVIEW}

Thirty-two studies were identified between 1990 and 2012 examining EOR and high-grade glioma patient outcomes (Shibamoto et al., 1990; Vecht et al., 1990; Hollerhage et al., 1991; Phillips et al., 1991; Sandberg-Wollheim et al., 1991; Curran et al., 1992; Duncan et al., 1992; Prados et al., 1992; Dinapoli et al., 1993; Huber et al., 1993; Simpson et al., 1993; Jeremic et al., 1994; Warnke et al., 1994; Nitta and Sato, 1995; Barker et al., 1996; Kowalczuk et al., 1997; Keles et al., 1999, 2006; Buckner et al., 2001; Lacroix et al., 2001; Levin et al., 2002; Puduvalli et al., 2003; Tortosa et al., 2003; Lamborn et al., 2004; Brown et al., 2005; Pope et al., 2005; Stark et al., 2005; Ushio et al., 2005; Nomiya et al., 2007). Most, but not all, studies used standard WHO grading criteria; other grading systems were utilized in a minority of reports (Dinapoli et al., 1993; Levin et al., 2002; Stark et al., 2005). Five studies used volumetric analysis to determine EOR; the other 27 studies used a combination of $2 \mathrm{D}$ postoperative imaging and surgeon judgment to create categories such as gross total resection (GTR), STR, partial resection $(\mathrm{PR})$, etc.

\section{HIGH-GRADE GLIOMA VOLUMETRIC STUDIES}

Among the five volumetric studies, three $(N=1,023$, range 107500 patients) demonstrated a significant survival benefit for increasing EOR (Table 1; Keles et al., 1999; Lacroix et al., 2001; Sanai et al., 2011). These three positive studies examined the value of EOR in GBM patients only. GTR (EOR = 100\%) was associated with a 2- to 8-month increased survival benefit compared to STRs $(\mathrm{EOR}=50-98 \%)$, depending on series. Two volumetric studies ( $N=110$ and 102 , respectively) showed no patient benefit with increasing EOR, although one study did trend toward increased patient survival with increased EOR despite statistical non-significance (Pope et al., 2005; Keles et al., 2006).

\section{HIGH-GRADE GLIOMA NON-VOLUMETRIC STUDIES}

Seventeen non-volumetric EOR studies ( $N=4,992$, range 86-949 patients) demonstrated a survival benefit associated with increased EOR using univariate or multivariate analyses (Table 2; Shibamoto et al., 1990; Vecht et al., 1990; Curran et al., 1992; Dinapoli et al., 1993; Simpson et al., 1993; Jeremic et al., 1994; Nitta and Sato, 1995; Barker et al., 1996; Buckner et al., 2001; Lamborn et al., 2004; Brown et al., 2005; Stark et al., 2005; Ushio et al., 2005; Nomiya et al., 2007; Stummer et al., 2008; McGirt et al., 2009a; 
Table 2 | Positive, non-volumetric studies of EOR in high-grade glioma.

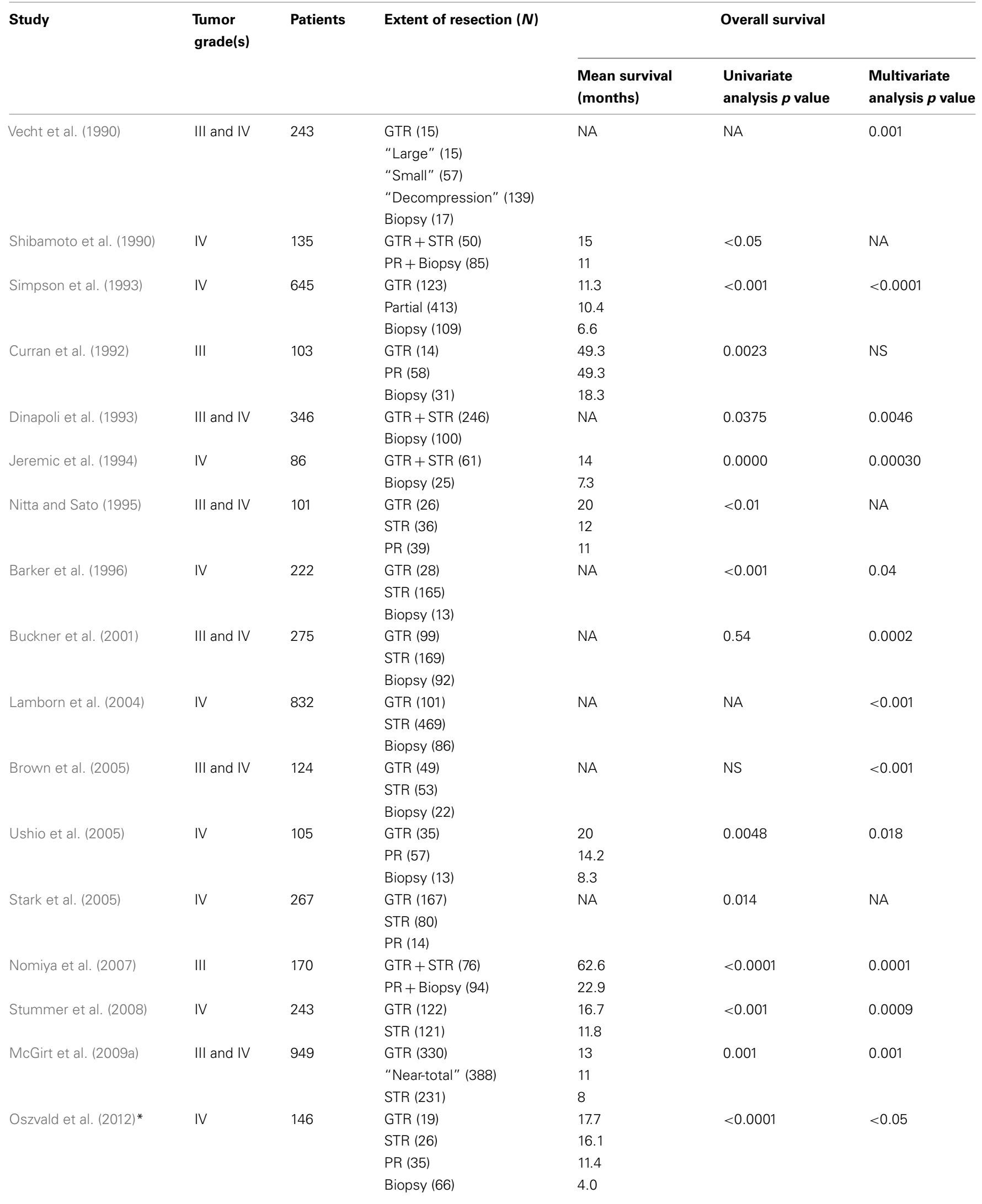

*Significant for patients aged over 65 years only. 
Table 3 | Negative, non-volumetric studies of EOR in high-grade glioma.

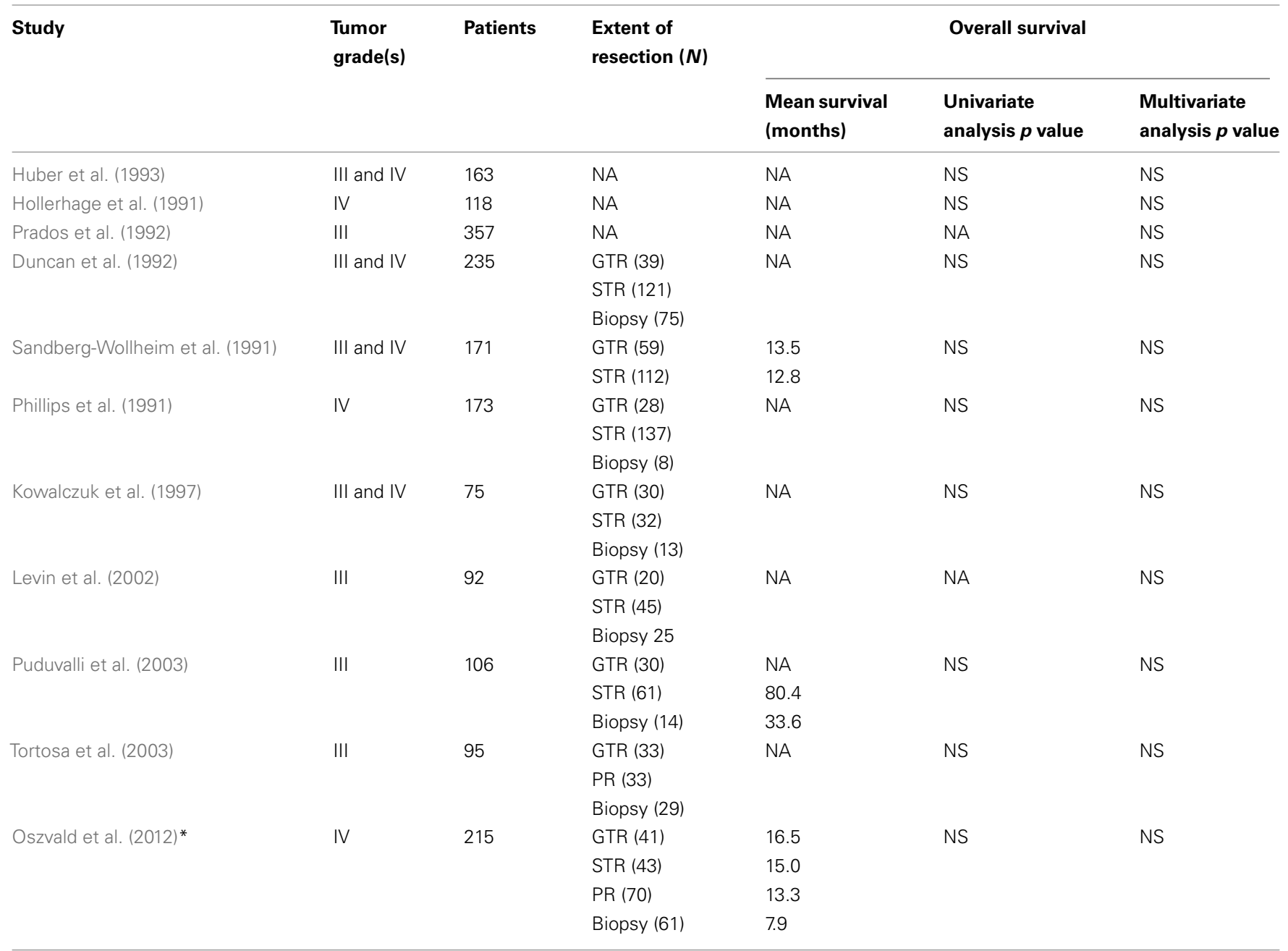

*Non-significant for patients aged under 65 years only.

Table 4 | Volumetric EOR studies in low-grade glioma.

\begin{tabular}{|c|c|c|c|c|c|}
\hline \multirow[t]{2}{*}{ Study } & \multirow[t]{2}{*}{ Patients } & \multirow{2}{*}{$\begin{array}{l}\text { Extent of } \\
\text { resection }(N)\end{array}$} & \multicolumn{3}{|c|}{ 5-Year overall survival } \\
\hline & & & 5-Year survival & $\begin{array}{l}\text { Univariate } \\
\text { analysis } p \text { value }\end{array}$ & $\begin{array}{l}\text { Multivariate } \\
\text { analysis } p \text { value }\end{array}$ \\
\hline \multirow[t]{2}{*}{ van Veelen et al. (1998) } & 90 & $>75 \%(13)$ & $62 \%$ & 0.002 & 0.04 \\
\hline & & $<75 \%(59)$ & $18 \%$ & & \\
\hline \multirow[t]{5}{*}{ Smith et al. (2008) } & 216 & $0-40 \%(21)$ & NA & NA & $<0.001$ \\
\hline & & $41-69 \%(39)$ & NA & & \\
\hline & & $70-89 \%(55)$ & NA & & \\
\hline & & $90-99 \%(26)$ & $97.0 \%$ & & \\
\hline & & $100 \%(75)$ & $98.0 \%$ & & \\
\hline
\end{tabular}


Table 5 | Positive low grade non-volumetric studies.

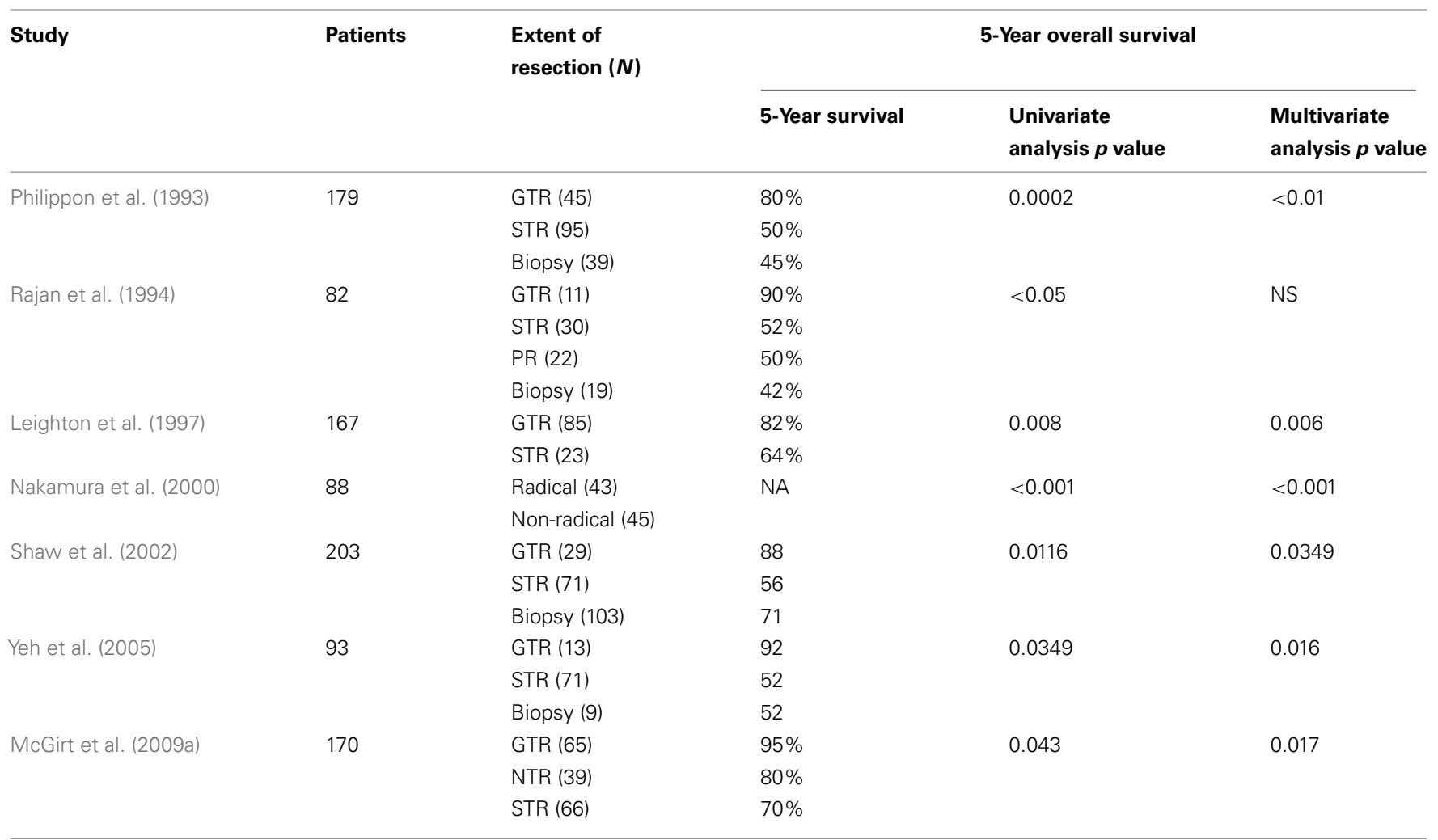

Table 6 | Negative, non-volumetric studies of EOR in low-grade glioma.

\begin{tabular}{|c|c|c|c|c|c|}
\hline \multirow[t]{2}{*}{ Study } & \multirow[t]{2}{*}{ Patients } & \multirow{2}{*}{$\begin{array}{l}\text { Extent of } \\
\text { resection }(N)\end{array}$} & \multicolumn{3}{|c|}{ 5-Year overall survival } \\
\hline & & & 5-Year survival & $\begin{array}{l}\text { Univariate } \\
\text { analysis } p \text { value }\end{array}$ & $\begin{array}{l}\text { Multivariate } \\
\text { analysis p value }\end{array}$ \\
\hline Johannesen et al. (2003) & 993 & $\begin{array}{l}\text { GTR (173) } \\
\text { STR (689) } \\
\text { Biopsy (131) }\end{array}$ & NA & NS & NS \\
\hline
\end{tabular}

Oszvald et al., 2012). Due to heterogeneity in EOR classification schemes, however, a more detailed meta-analysis of these series is not possible. Similar to the volumetric studies discussed above, overall survival was (depending on series) 0.9-8.0 months longer following GTR as compared to following STR. Of the 14 studies that utilized multivariate analysis to control for age, performance status, and use of adjuvant therapy, only one such analysis (Curran et al., 1992) subsequently rendered EOR nonsignificant. All other studies using multivariate analysis found greater EOR to independently be associated with improved survival (Table 2). Of note, four studies found EOR to only be associated with increased patient survival in multivariate analysis, but not univariate analysis. Conversely, 11 non-volumetric studies ( $N=1800$, range 75-357 patients) demonstrated no overall survival benefit associated with increased EOR using either univariate or multivariate analysis (Table 3; Hollerhage et al., 1991; Phillips et al., 1991; Sandberg-Wollheim et al., 1991; Duncan et al., 1992;
Prados et al., 1992; Huber et al., 1993; Kowalczuk et al., 1997; Levin et al., 2002; Puduvalli et al., 2003; Tortosa et al., 2003; Oszvald et al., 2012). Potential confounders such as use of chemotherapy and radiation therapy varied widely between publications, but did not differ significantly among patients receiving greater or lesser EOR in any individual series.

\section{LOW-GRADE GLIOMA STUDIES TO DATE - AN OVERVIEW}

Eleven studies between 1990 and 2012 evaluated EOR and patient overall and/or progression-free survival for low-grade gliomas (Philippon et al., 1993; Rajan et al., 1994; Leighton et al., 1997; van Veelen et al., 1998; Nakamura et al., 2000; Shaw et al., 2002; Johannesen et al., 2003; Claus et al., 2005; Yeh et al., 2005; Smith et al., 2008; McGirt et al., 2009a). Histologically, the majority of tumors were low-grade astrocytomas, but oligoastrocytomas and oligodendrogliomas were included as a minority of tumors in 10 studies. Three studies used volumetric analysis to determine EOR; 
the other eight studies used either two-dimensional postoperative imaging parameters or surgeon judgment.

\section{LOW-GRADE GLIOMAS - VOLUMETRIC STUDIES}

All three studies to date using volumetric analysis to determine EOR in low-grade glioma patients $(N=462$, range 90-216 patients) have demonstrated a benefit to increasing EOR in univariate and/or in multivariate analysis (Table 4; van Veelen et al., 1998; Claus et al., 2005; Smith et al., 2008). Five-year overall survival was improved in all studies; median survival and time to malignant progression was not always reported. However, in the most recent report by Smith et al. (2008) greater EOR was also predictive of increased malignant progression-free survival.

\section{LOW-GRADE GLIOMAS - NON-VOLUMETRIC STUDIES}

Among the eight non-volumetric studies examining the survival benefit associated with EOR for low-grade glioma patients, seven ( $N=982$, range 82-203 patients) demonstrated a benefit with increasing EOR (Table 5; Philippon et al., 1993; Rajan et al., 1994; Leighton et al., 1997; Nakamura et al., 2000; Shaw et al., 2002; Yeh et al., 2005; McGirt et al., 2009a). Five-year overall survival was markedly increased in all series, increasing from $50-70 \%$ in STRs to $80-95 \%$ in GTR. Cytoreduction remained a significant predictor in the multivariate analyses of six of the seven positive studies (Table 5). Malignant progression-free survival was improved in patients undergoing GTR in the one series that specifically commented upon malignant progression (McGirt et al., 2009a). One large study $(N=992)$ found no significant difference between gross total and subtotal resections in 5-year patient survival (Table 6; Johannesen et al., 2003). As expected, the use of radiation therapy and chemotherapy varied widely between studies. In seven studies, multivariate analysis adjusted for adjuvant radiation therapy, although, in two reports, $100 \%$ of patients received postoperative radiation therapy regardless of EOR. In one study (McGirt et al., 2009a), no patient received postoperative radiation therapy prior to disease progression.

\section{DISCUSSION}

To date, no Level I evidence exists comparing EOR and glioma patient outcome. In the modern neurosurgical era, completion of a randomized, placebo-controlled trial examining high-grade glioma EOR remains unlikely. The literature from the last two decades strongly suggests that increasing EOR improves glioma patient survival. This may be particularly important in the surgical resection of low-grade gliomas, where every volumetric EOR study identified and reviewed here has demonstrated survival benefit. Multiple studies have also found a decrease in malignant progression for these low-grade lesions with greater EOR, suggesting a surgical alteration of tumor biology (Smith et al., 2008; McGirt et al., 2009a). This favorable change in the natural history of these lesions from aggressive resection deserves further investigation.

For high-grade gliomas, there is heterogeneity in the EOR literature. The strongest evidence for EOR improving outcome in GBM comes from the randomized trial of 5-ALA published in
2006 by the ALA-Glioma Study Group (Stummer et al., 2006). Patients undergoing surgery with the use of 5-ALA had improved rates of GTR as well as increased 6-month PFS compared to traditional microsurgical resection; however, because patients were randomized to treatment group (5-ALA vs. none) rather than resection category (GTR vs. subtotal), and because subsequent postoperative care was not universal amongst patients with GTR and STRs, this study is not Level I evidence for EOR alone improving outcome. Nevertheless, an extensive retrospective analysis of the study data by the original authors re-stratifying study patients to GTR or STR groups identified complete resection (GTR) as an independent variable in overall survival upon multivariate analysis (Stummer et al., 2008). The ALA-Glioma Study Group data may therefore be considered Level $2 \mathrm{~b}$ evidence for increasing EOR improving GBM patient outcome - the highest level of evidence from any EOR publication to date. Despite these findings, several retrospective volumetric studies and numerous non-volumetric studies have shown no benefit to increased EOR in high-grade glioma patients. Nevertheless, the overwhelming majority (11 of 14) of large high-grade glioma series (>200 patients), do show survival benefit with greater EOR (Vecht et al., 1990; Duncan et al., 1992; Prados et al., 1992; Dinapoli et al., 1993; Simpson et al., 1993; Barker et al., 1996; Buckner et al., 2001; Lacroix et al., 2001; Lamborn et al., 2004; Stark et al., 2005; Stummer et al., 2008; McGirt et al., 2009a; Sanai et al., 2011; Oszvald et al., 2012). Thus, it remains possible that most of these negative small series may be underpowered to detect a clinically and statistically significant difference.

Balancing cytoreduction with the risk of neurological morbidity is a common theme in many recent reports. Although no study has directly compared this relationship, retrospective studies demonstrate an association between new postoperative deficit and decreased overall survival or worsened functional outcome (McGirt et al., 2009b; Gulati et al., 2011). Interestingly, several large series have demonstrated no difference in new postoperative neurological deficits between patients undergoing GTR vs. subtotal glioma resection (Stummer et al., 2008; McGirt et al., 2009b; Sanai et al., 2011). However, in an analysis of neurological morbidity provided by the ALA-Glioma Study Group, patients in the ALA group had more frequent deterioration on the NIH-Stroke Scale at $48 \mathrm{~h}$ (Stummer et al., 2011). Importantly, techniques such as intraoperative cortical stimulation mapping may help mitigate the risks of aggressive glioma resection in eloquent territories (De Witt Hamer et al., 2012).

Many other critical questions remain unanswered. The effect of EOR for different histological subtypes of tumor must be studied, as tumor biology unquestionably plays a role in determining its response to cytoreduction and, perhaps, its ease of obtaining GTR. Similarly, tumor biomarkers known to predict response to adjuvant therapy or overall survival (such as $1 \mathrm{p} / 19 \mathrm{q}, \mathrm{IDH} 1 / 2$, and MGMT-methylation) should also be incorporated into future analyses. Also, it is unclear whether the correlation between EOR and survival holds true for both first-time and recurrent operations in either low- or high-grade patients. Lastly, the efficacy of emerging adjuvant therapies, such as bevacizumab, should also be studied in the context of EOR. 


\section{CONCLUSION}

Our review of all studies in the modern neurosurgical era for both low- and high-grade adult supratentorial gliomas highlights recent literature that associate more extensive microsurgical resection with improved life expectancy. In GBM, this level of evidence reaches Level $2 \mathrm{~b}$ from retrospective analysis of randomized trial data; most evidence is Level 3 from retrospective case series. In addition to providing greater overall survival, more aggressive

\section{REFERENCES}

Barker, F. G. II, Prados, M. D., Chang, S. M., Gutin, P. H., Lamborn, K. R., Larson, D. A., et al. (1996). Radiation response and survival time in patients with glioblastoma multiforme. J. Neurosurg. 84, 442-448.

Brown, P. D., Maurer, M. J., Rummans, T. A., Pollock, B. E., Ballman, K. V., Sloan, J. A., et al. (2005). A prospective study of quality of life in adults with newly diagnosed high-grade gliomas: the impact of the extent of resection on quality of life and survival. Neurosurgery 57, 495-504; discussion 495-504.

Buckner, J. C., Schomberg, P. J., McGinnis, W. L., Cascino, T. L., Scheithauer, B. W., O'Fallon, J. R., et al. (2001). A phase III study of radiation therapy plus carmustine with or without recombinant interferon-alpha in the treatment of patients with newly diagnosed high-grade glioma. Cancer 92, 420-433.

Claus, E. B., Horlacher, A., Hsu, L., Schwartz, R. B., Dello-Iacono, D., Talos, F., et al. (2005). Survival rates in patients with low-grade glioma after intraoperative magnetic resonance image guidance. Cancer 103, 1227-1233.

Curran, W. J. Jr., Scott, C. B., Horton, J., Nelson, J. S., Weinstein, A. S., Nelson, D. F., et al. (1992). Does extent of surgery influence outcome for astrocytoma with atypical or anaplastic foci (AAF)? A report from three Radiation Therapy Oncology Group (RTOG) trials. J. Neurooncol. 12, 219-227.

De Witt Hamer, P. C., Robles, S. G., Zwinderman, A. H., Duffau, H., and Berger, M. S. (2012). Impact of intraoperative stimulation brain mapping on glioma surgery outcome: a meta-analysis. J. Clin. Oncol. 30, 2559-2565.

Dinapoli, R. P., Brown, L. D., Arusell, R. M., Earle, J. D., O'Fallon, J. R., Buckner, J. C., et al. (1993). Phase III comparative evaluation of PCNU and carmustine combined with radiation therapy for high-grade glioma. J. Clin. Oncol. 11, 1316-1321.

Duncan, G. G., Goodman, G. B., Ludgate, C. M., and Rheaume, D. E. (1992). The treatment of adult supratentorial high grade astrocytomas. J. Neurooncol. 13, 63-72.

Gulati, S., Jakola, A. S., Nerland, U. S., Weber, C., and Solheim, O. (2011). The risk of getting worse: surgically acquired deficits, perioperative complications, and functional outcomes after primary resection of glioblastoma. World Neurosurg. 76, 572-579.

Hollerhage, H. G., Zumkeller, M., Becker, M., and Dietz, H. (1991). Influence of type and extent of surgery on early results and survival time in glioblastoma multiforme. Acta Neurochir. 113, 31-37.

Huber, A., Beran, H., Becherer, A., Prosenc, N., and Witzmann, A. (1993). Supratentorial glioma: analysis of clinical and temporal parameters in 163 cases. Neurochirurgia 36, 189-193.

Jeremic, B., Grujicic, D., Antunovic, V., Djuric, L., Stojanovic, M., and Shibamoto, Y. (1994). Influence of extent of surgery and tumor location on treatment outcome of patients with glioblastoma multiforme treated with combined modality approach. J. Neurooncol. $21,177-185$.

Johannesen, T. B., Langmark, F., and Lote, K. (2003). Progress in long-term survival in adult patients with supratentorial lowgrade gliomas: a population-based study of 993 patients in whom tumors were diagnosed between 1970 and 1993. J. Neurosurg. 99, 854-862.

Keles, G. E., Anderson, B., and Berger, M. S. (1999). The effect of extent of resection on time to tumor progression and survival in patients with glioblastoma multiforme of the cerebral hemisphere. Surg. Neurol. 52, 371-379.

Keles, G. E., Chang, E. F., Lamborn, K. R., Tihan, T., Chang, C. J., Chang, S. M., et al. (2006). Volumetric extent of resection and residual contrast enhancement on initial surgery as predictors of outcome in adult patients with hemispheric anaplastic astrocytoma. J. Neurosurg. 105, 34-40.

resections for low-grade gliomas may also impact the natural history of the disease, favorably altering its risk profile for malignant transformation. A prospective, randomized study using modern intraoperative techniques and standardized perioperative adjuncts remains the gold-standard in settling the controversy, but such a trial may never occur. For the time being, retrospective matched studies, retrospective reviews of randomized trials, or prospective observational trials remain the most practical solutions.

Kowalczuk, A., Macdonald, R. L., Amidei, C., Dohrmann, G. III, Erickson, R. K., Hekmatpanah, J., et al. (1997). Quantitative imaging study of extent of surgical resection and prognosis of malignant astrocytomas. Neurosurgery 41, 1028-1036; discussion 36-38.

Kubben, P. L., ter Meulen, K. J., Schijns, O. E., ter Laak-Poort, M. P., van Overbeeke, J. J., and van Santbrink, H. (2011). Intraoperative MRIguided resection of glioblastoma multiforme: a systematic review. Lancet Oncol. 12, 1062-1070.

Lacroix, M., Abi-Said, D., Fourney, D. R., Gokaslan, Z. L., Shi, W., DeMonte, F., et al. (2001). A multivariate analysis of 416 patients with glioblastoma multiforme: prognosis, extent of resection, and survival. J. Neurosurg. 95, 190-198.

Lamborn, K. R., Chang, S. M., and Prados, M. D. (2004). Prognostic factors for survival of patients with glioblastoma: recursive partitioning analysis. Neurooncology 6, 227-235.

Leighton, C., Fisher, B., Bauman, G., Depiero, S., Stitt, L., MacDonald, D., et al. (1997). Supratentorial lowgrade glioma in adults: an analysis of prognostic factors and timing of radiation. J. Clin. Oncol. 15, 1294-1301.

Levin, V. A., Yung, W. K., Bruner, J., Kyritsis, A., Leeds, N., Gleason, M. J., et al. (2002). Phase II study of accelerated fractionation radiation therapy with carboplatin followed by PCV chemotherapy for the treatment of anaplastic gliomas. Int. J. Radiat. Oncol. Biol. Phys. 53, 58-66.

McGirt, M. J., Chaichana, K. L., Gathinji, M., Attenello, F. J., Than, K. Olivi, A., et al. (2009a). Independent association of extent of resection with survival in patients with malignant brain astrocytoma. J. Neurosurg. 110, 156-162.

McGirt, M. J., Mukherjee, D. Chaichana, K. L., Than, K. D., Weingart, J. D., and QuinonesHinojosa, A. (2009b). Association of surgically acquired motor and language deficits on overall survival after resection of glioblastoma multiforme. Neurosurgery 65, 463-469; discussion 9-70.
Nakamura, M., Konishi, N., Tsunoda, S., Nakase, H., Tsuzuki, T., Aoki, H., et al. (2000). Analysis of prognostic and survival factors related to treatment of low-grade astrocytomas in adults. Oncology 58, 108-116.

Nitta, T., and Sato, K. (1995). Prognostic implications of the extent of surgical resection in patients with intracranial malignant gliomas. Cancer 75 , 2727-2731.

Nomiya, T., Nemoto, K., Kumabe, T., Takai, Y., and Yamada, S. (2007). Prognostic significance of surgery and radiation therapy in cases of anaplastic astrocytoma: retrospective analysis of 170 cases. J. Neurosurg. 106, 575-581.

Oszvald, A., Güresir, E., Setzer, M., Vatter, H., Senft, C., Seifert, V., et al. (2012). Glioblastoma therapy in the elderly and the importance of the extent of resection regardless of age. J. Neurosurg. 116, 357-364.

Philippon, J. H., Clemenceau, S. H., Fauchon, F. H., and Foncin, J. F. (1993). Supratentorial low-grade astrocytomas in adults. Neurosurgery 32, 554-559.

Phillips, T. L., Levin, V. A., Ahn, D. K., Gutin, P. H., Davis, R. L., Wilson, C. B., et al. (1991). Evaluation of bromodeoxyuridine in glioblastoma multiforme: a Northern California Cancer Center Phase II study. Int. J. Radiat. Oncol. Biol. Phys. 21, 709-714.

Pope, W. B., Sayre, J., Perlina, A., Villablanca, J. P., Mischel, P. S., and Cloughesy, T. F. (2005). MR imaging correlates of survival in patients with high-grade gliomas. AJNR Am. J. Neuroradiol. 26, 2466-2474.

Prados, M. D., Gutin, P. H., Phillips, T. L., Wara, W. M., Larson, D. A., Sneed, P. K., et al. (1992). Highly anaplastic astrocytoma: a review of 357 patients treated between 1977 and 1989. Int. J. Radiat. Oncol. Biol. Phys. 23, 3-8.

Puduvalli, V. K., Hashmi, M., McAllister, L. D., Levin, V. A., Hess, K. R., Prados, M., et al. (2003). Anaplastic oligodendrogliomas: prognostic factors for tumor recurrence and survival. Oncology 65, 259-266. 
Rajan, B., Pickuth, D., Ashley, S., Traish, D., Monro, P., Elyan, S., et al. (1994). The management of histologically unverified presumed cerebral gliomas with radiotherapy. Int. J. Radiat. Oncol. Biol. Phys. 28, 405-413.

Sanai, N., and Berger, M. S. (2008). Glioma extent of resection and its impact on patient outcome. Neurosurgery 62, 753-64; discussion 264-266.

Sanai, N., and Berger, M. S. (2009). Operative techniques for gliomas and the value of extent of resection. Neurotherapeutics 6, 478-486.

Sanai, N., and Berger, M. S. (2010). Intraoperative stimulation techniques for functional pathway preservation and glioma resection. Neurosurg. Focus 28, E1.

Sanai, N., Polley, M. Y., McDermott, M. W., Parsa, A. T., and Berger, M. S. (2011). An extent of resection threshold for newly diagnosed glioblastomas. J. Neurosurg. 115, 3-8.

Sandberg-Wollheim, M., Malmstrom, P., Stromblad, L. G., Anderson, H., Borgström, S., Brun, A., et al. (1991). A randomized study of chemotherapy with procarbazine, vincristine, and lomustine with and without radiation therapy for astrocytoma grades 3 and/or 4. Cancer 68, 22-29.

Shaw, E., Arusell, R., Scheithauer, B., O'Fallon, J., O'Neill, B., Dinapoli, R., et al. (2002). Prospective randomized trial of low- versus highdose radiation therapy in adults with supratentorial low-grade glioma: initial report of a North Central Cancer Treatment Group/Radiation
Therapy Oncology Group/Eastern Cooperative Oncology Group study. J. Clin. Oncol. 20, 2267-2276.

Shibamoto, Y., Yamashita, J., Takahashi, M., Yamasaki, T., Kikuchi, H., and Abe, M. (1990). Supratentorial malignant glioma: an analysis of radiation therapy in 178 cases. Radiother. Oncol. 18, 9-17.

Simpson, J. R., Horton, J., Scott, C., Curran, W. J., Rubin, P., Fischbach, J., et al. (1993). Influence of location and extent of surgical resection on survival of patients with glioblastoma multiforme: results of three consecutive Radiation Therapy Oncology Group (RTOG) clinical trials. Int. J. Radiat. Oncol. Biol. Phys. 26 239-244.

Smith, J. S., Chang, E. F., Lamborn, K. R., Schwartz, R. B., Dello-Iacono, D., Talos, F., et al. (2008). Role of extent of resection in the longterm outcome of low-grade hemispheric gliomas. J. Clin. Oncol. 26, 1338-1345.

Stark, A. M., Nabavi, A., Mehdorn, H. M., and Blomer, U. (2005). Glioblastoma multiforme-report of 267 cases treated at a single institution. Surg. Neurol. 63, 162-169; discussion 9.

Stummer, W., Pichlmeier, U., Meinel, T., Wiestler, O. D., Zanella, F., and Reulen, H. J. (2006). Fluorescence-guided surgery with 5-aminolevulinic acid for resection of malignant glioma: a randomised controlled multicentre phase III trial. Lancet Oncol. 7, 392-401.

Stummer, W., Reulen, H. J., Meinel, T., Pichlmeier, U., Schumacher, W., Tonn, J. C., et al. (2008). Extent of resection and survival in glioblastoma multiforme: identification of and adjustment for bias. Neurosurgery 62, 564-576; discussion 76.

Stummer, W., Tonn, J. C., Mehdorn, H. M., Nestler, U., Franz, K., Goetz, C., et al. (2011). Counterbalancing risks and gains from extended resections in malignant glioma surgery: a supplemental analysis from the randomized 5-aminolevulinic acid glioma resection study. Clinical article. J. Neurosurg. 114, 613-623.

Tortosa, A., Vinolas, N., Villa, S., Verger, E., Gil, J. M., Brell, M., et al. (2003) Prognostic implication of clinical, radiologic, and pathologic features in patients with anaplastic gliomas. Cancer 97, 1063-1071.

Ushio, Y., Kochi, M., Hamada, J., Kai, Y., and Nakamura, H. (2005). Effect of surgical removal on survival and quality of life in patients with supratentorial glioblastoma. Neurol. Med. Chir. (Tokyo) 45, 454-460; discussion 60-61.

van Veelen, M. L., Avezaat, C. J. Kros, J. M., van Putten, W., and Vecht, C. (1998). Supratentorial low grade astrocytoma: prognostic factors, dedifferentiation, and the issue of early versus late surgery. J. Neurol. Neurosurg. Psychiatr. 64, 581-587.

Vecht, C. J., Avezaat, C. J., van Putten, W. L., Eijkenboom, W. M., and Stefanko, S. Z. (1990). The influence of the extent of surgery on the neurological function and survival in malignant glioma. A retrospective analysis in 243 patients. J. Neurol. Neurosurg. Psychiatr. 53, 466-471.

Warnke, P. C., Kreth, F. W., Scheremet, R., and Ostertag, C. B. (1994)
Response to Drs. Simpson, et al: influence of location and extent of surgical resection on survival of patients with glioblastoma multiforme: results of three consecutive Radiation Therapy Oncology Group clinical trials. Int. J. Radiat. Oncol. Biol. Phys. 29, 220.

Yeh, S. A., Ho, J. T., Lui, C. C., Huang, Y. J., Hsiung, C. Y., and Huang, E. Y. (2005). Treatment outcomes and prognostic factors in patients with supratentorial low-grade gliomas. Br. J. Radiol. 78, 230-235.

Conflict of Interest Statement: The authors declare that the research was conducted in the absence of any commercial or financial relationships that could be construed as a potential conflict of interest.

Received: 25 July 2012; paper pending published: 18 August 2012; accepted: 23 September 2012; published online: 18 October 2012.

Citation: Hardesty DA and Sanai N (2012) The value of glioma extent of resection in the modern neurosurgical era. Front. Neur. 3:140. doi: 10.3389/fneur.2012.00140

This article was submitted to Frontiers in Neuro-oncology, a specialty of Frontiers in Neurology.

Copyright (๑ 2012 Hardesty and Sanai. This is an open-access article distributed under the terms of the Creative Commons Attribution License, which permits use, distribution and reproduction in other forums, provided the original authors and source are credited and subject to any copyright notices concerning any third-party graphics etc. 